\title{
O PAPEL DO DIRETOR DAS ESCOLAS PÚBLICAS DA REDE MUNICIPAL DE SANTO AMARO (BA)
}

\author{
THE ROLE OF THE DIRECTOR OF THE PUBLIC SCHOOLS OF SANTO \\ AMARo (BA)
}

\begin{abstract}
Sergio Henrique Conceicao
Doutor em Educação. Professor Adjunto do Departamento de Ciências Humanas e Tecnologias (DCHT), Campus XIX - Camaçari e do Programa de Pós-Graduação em Gestão e Tecnologias na Universidade do Estado da Bahia (UNEB) shconceicao@uneb.br
\end{abstract}

Hirlana Freitas de Lemos Mestra em Gestão e Tecnologias aplicadas à Educação, Professora, Secretaria Municipal de Educação de Santo Amaro, Santo Amaro (BA) - BRASIL hirlanafr@hotmail.com

Resumo: Reconhecendo a relevância da função do diretor escolar, sua inserção no trabalho coletivo e colaborativo no âmbito das escolas, o presente trabalho de natureza documental e exploratória investigou aspectos acerca do papel do diretor das escolas públicas da rede municipal de Santo Amaro (BA) sob a perspectiva do paradigma multidimensional (SANDER, 1995, 2007). Os resultados da investigação evidenciam relativa adesão aos pressupostos teóricos do paradigma dimensional e o reconhecimento dessas dimensões (econômicas, políticas, pedagógicas e culturais), com prevalência das dimensões política e cultural sobre as demais. Identificou lacuna normativa e ausência de práticas sistematizadas de capacitação e aperfeiçoamento, voltadas ao desenvolvimento do trabalho dos diretores e sua formação em serviço, na perspectiva de efetivação de seu papel institucional no âmbito daquela rede educacional pública e na busca do reconhecimento do propósito pedagógico de suas práticas profissionais.

Palavras chave: Gestão escolar; Administração escolar; Diretor escolar

Abstract: Recognizing the relevance of the role of the school director, his involvement in collective and collaborative work within schools, this documentary and exploratory work investigated aspects about the role of the director of public schools of the municipal network of Santo Amaro (BahiaBrazil) under the perspective of the multidimensional paradigm (SANDER, 1995, 2007). The results of the research evidenced a relative adherence to the theoretical presuppositions of the dimensional paradigm and the recognition of these dimensions (economic, political, pedagogic and cultural), with prevalence of the political and cultural dimensions over the others. It identified a normative gap and lack of systematized training and improvement practices, focused on the development of the work of the directors and their in-service training, with a view to realizing their institutional role within the public educational network and seeking recognition of the pedagogical purpose of their practices.

Keywords: School management; School administration; School director 


\section{Introdução}

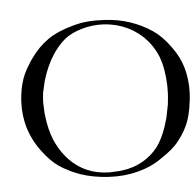
s estudos científicos têm nos advertido quanto a compreensão da gestão escolar muitas vezes pautadas a partir das experiências da administração privada adaptadas, geralmente, distantes do propósito pedagógico das unidades escolares, do princípio democrático que devem nortear suas práticas (BRASIL, 1988) e indiferente a complexidade das relações ensino-aprendizagem que são vivenciadas no cotidiano escolar (BARROSO, 1995; LIMA, 2001; PARO, 2010; LÜCK, 2009).

Os estudos de Sander (1995) sistematizam o processo de construção histórica do campo da gestão educacional ou administração educacional, no Brasil e na América Latina, como uma dinâmica de construção e reconstrução teórica pautada por influências dos outros campos científicos. Nesse sentido, os estudos de Sander $(1995,2007)$ concebem a educação e a administração educacional como realidades globais constituídas por dimensões múltiplas e articuladas propondo o paradigma multidimensional como uma construção heurística possivelmente capaz de refletir, aspectos ideológicos, culturais e políticos, tanto em perspectiva técnica quanto pedagógica e econômica, articuladas mutuamente no âmbito das práticas processados nos sistemas públicos de educação.

A partir da compreensão da construção do campo teórico da administração escolar, aqui reconhecida como sinônimo da gestão escolar (BARROSO, 1995), esse trabalho elegeu o paradigma multidimensional de Sander $(1995,2007)$ como base teórica para a pesquisa do fenômeno do papel do diretor escolar no âmbito das escolas da zona urbana de Santo Amaro (BA), município da região do recôncavo baiano.

O trabalho buscou investigar como estão articuladas político-normativamente as orientações relacionadas às práticas do diretor escolar no âmbito das escolas da zona urbana da rede municipal de educação de Santo Amaro (BA) e como essas práticas se efetivam no cotidiano escolar (LEMOS, 2017).

Para o alcance desse objetivo, o trabalho realizou uma análise documental da legislação vigente no município de Santo Amaro (BA), conhecendo e compreendendo os documentos que normatizam a ação do diretor escolar, e até que ponto tais documentos organizam e orientam suas práticas, e, se possuem em seu escopo indícios que identificam a natureza multidimensional do seu trabalho e as diversas funções desempenhadas pelo gestor no seu cotidiano profissional. Em caráter complementar, a pesquisa realizou escuta desses sujeitos através de entrevistas estruturadas, no sentido de identificar como a partir dos marcos normativos publicados, sua formação acadêmica e profissional, e, a dinâmica escolar vivenciada, efetivam suas práticas dirigentes.

O trabalho está organizado em cinco seções, essa primeira seção introdutória, que apresentamos o tema e objetivos da pesquisa, seguida de uma seção de referencial teórico, onde constam os pressupostos teóricos da compreensão da administração escolar e do paradigma multidimensional, a terceira seção, que evidenciamos a metodologia desenvolvida na pesquisa, a 
quarta seção, com os resultados obtidos no estudo, a quinta seção com considerações e recomendações finais da pesquisa, e, por fim, as referências utilizadas.

\section{Referencial teórico}

Convivem no Brasil, tanto perspectivas de gestão educacional com ênfase em aspectos mais aproximados da perspectiva empresarial quanto abordagens que enfatizam aqueles mais aproximados da perspectiva política (BARROSO, 1995; LIMA, 2001; PARO, 2010; LÜCK, 2009).

Logo, percebe-se um amplo campo de concepções da gestão educacional e escolar em diferentes arranjos institucionais convivendo nas unidades escolares, concepções, geralmente atrofiadas de qualquer compromisso pedagógico ou princípio democrático que lhes confiram legitimidade (BARROSO, 1995; NOGUEIRA, 2002).

O paradigma multidimensional de Sander $(1995,2007)$ estabelece que a educação e a administração escolar são realidades globais, multidimensionais cujas as dimensões políticas, econômicas, cultuais e pedagógicas estão dialeticamente articuladas entre si, e, historicamente constituídas.

A presente pesquisa, desse modo, compreende que o diretor escolar absorve diversas responsabilidades, desempenha múltiplas funções, as quais, por sua vez, são pautadas historicamente na construção do campo da administração educacional e escolar, consequentemente, repercutindo em suas práticas profissionais e no cotidiano escolar (LEMOS,2017).

O trabalho do diretor, dado esse entendimento, está relacionado com a dimensão econômica (utilização de recursos materiais), política (mediação dos interesses de estudantes, professores, profissionais, pais de alunos e comunidade), cultural (reconhecimento dos valores, crenças e tradições locais), e, especialmente, pedagógica (estratégias de ensino-aprendizagem e de mediação de conhecimento), resultando, possivelmente, na efetivação do paradigma multidimensional, guardando, em proporção, especificidades no cotidiano das escolas e o trabalho do diretor (SANDER 2007).

Essa pesquisa compreende a administração ou gestão escolar, aqui tomadas como sinônimos, enquanto expressão do trabalho complexo e específico de natureza técnica e profissional, realizado no âmbito da escola; conjunto de práticas democraticamente referenciadas de propósito pedagógico, que buscam elaborar, acompanhar e efetivar estratégicas de ensino-aprendizagem, capazes de contribuir para a formação humanística, cultural, política e profissional de crianças, jovens e adultos que frequentam unidades escolares, para qual recursos de natureza econômica, tecnológica, política e cultural são direcionados equilibradamente de forma eficiente, eficaz, efetiva e relevante (PARO, 
1993; SILVA JÚNIOR, 1993; BARROSO, 1995; NOGUEIRA, 2002; TEIXEIRA, 2005; SANDER, 2007; CONCEIÇÃO, 2016, PARENTE, 2016).

O papel do diretor então consiste em mediar os recursos materiais e imateriais a disposição da escola a partir de diretrizes democráticas que devem pautar sua atuação, no sentido de alcançar propósitos pedagógicos, e práticas de ensino-aprendizagem que correspondam às demandas da comunidade escolar pelo direito a educação que consideram o conjunto de crenças, valores e princípios culturais que temperam o conjunto das relações entre a escola, seus sujeitos e a comunidade em seu entorno.

Diante de um cenário desafiador da educação brasileira, e, em particular, da Bahia, do recôncavo baiano, recorte territorial assumido nesse trabalho, onde questões quanto a universalização da oferta de educação básica, (des)valorização dos profissionais da educação, evasão, distorção idadesérie, desempenho e proficiência escolar aquém do esperado, mecanismos de nomeação e designação dos diretores escolares e ausência de formação profissional e em serviço (CONCEIÇÃO, 2016; IBGE, 2016), o trabalho busca investigar a dinâmica da compreensão e efetivação do papel do diretor escolar em uma rede pública escolar a partir de seu aparato normativo, visão dos sujeitos e dos pressupostos teóricos consolidados na literatura científica.

\section{Metodologia}

O município de Santo Amaro, lócus do presente trabalho está localizado no interior do estado da Bahia, na região do recôncavo baiano, e, conforme dados do Instituto Brasileiro de Geografia e Estatística (IBGE, 2015), apresenta população estimada em 61.702 habitantes, e área da unidade territorial de $492,916 \mathrm{~km}^{2}$.

A pesquisa foi sistematizada, preliminarmente, com uma pesquisa bibliográfica, acompanhada de um estudo exploratório, por meio de análise documental da rede pública em documentos oficiais (estatutos, regimentos, leis) para entender como as práticas dos diretores dessa rede pública, prescritas na legislação municipal, reconhecem e efetivam uma gestão escolar de caráter multidimensional, ou seja, se as práticas prescritas reconhecem as dimensões econômicas, pedagógicas, políticas e culturais conforme preconizados nos pressupostos teóricos de Sander (1995, 2007).

O trabalho considera o acervo normativo municipal formado pela Lei $n^{\circ}$. 1432/2002: Estatuto do Magistério Público do Município de Santo Amaro; a Lei no . 1463/2003: Plano de Carreira e remuneração dos Servidores do Magistério Público do Município de Santo Amaro; a Lei nº. 1465/2003: Sistema Jurídico Único dos Servidores da Administração Direta, das Autarquias e das Fundações do Município de Santo Amaro e o Regimento Escolar Unificado apresentado pela 
e-ISSN: 2525-3514

Secretaria Municipal de educação, esporte e lazer em 2011 como arcabouços da análise documental (LEMOS, 2017).

A partir das categorias iniciais, fizemos o levantamento e aglutinações dos termos presentes, categorias intermediárias, e, posteriormente, estabelecemos uma correlação dessas categorias intermediárias com as dimensões econômica, pedagógica, política e cultural (SANDER, 2002) -

Quadro 1.

Quadro 1 - Convergência de conceitos/categorias para o Paradigma multidimensional

\begin{tabular}{|c|c|c|}
\hline $\begin{array}{c}\text { Conceitos } \\
\text { iniciais } \\
\text { (Categorias) }\end{array}$ & Conceitos intermediários & $\begin{array}{l}\text { Dimensões do Paradigma } \\
\text { multidimensional Sander }\end{array}$ \\
\hline $\begin{array}{l}\text { Conceitos } \\
\text { gerais }\end{array}$ & $\begin{array}{l}\text { Espaço, existência, movimento, ordem, quantidade, } \\
\text { relação, tempo. }\end{array}$ & Política \\
\hline Vida humana & $\begin{array}{l}\text { Ciclo da vida, corpo humano, emoções, inteligência, o } \\
\text { ser humano, percepções. }\end{array}$ & Cultural \\
\hline $\begin{array}{l}\text { Educação e } \\
\text { ensino }\end{array}$ & $\begin{array}{l}\text { Educação, ensino, graus acadêmicos, instituição de } \\
\text { ensino, lição, organização do ensino. }\end{array}$ & Pedagógica \\
\hline Indivíduo & $\begin{array}{l}\text { Comportamentos, ação, caráter, circunstâncias, } \\
\text { colaboração, estado de ânimo, imagem de si, maneiras } \\
\text { de agir, objetivos, razão, sentimentos, vontade. }\end{array}$ & Cultural \\
\hline $\begin{array}{l}\text { Emprego e } \\
\text { trabalho }\end{array}$ & $\begin{array}{l}\text { Identidade profissional, administração e remuneração } \\
\text { do pessoal, condições e organização do trabalho, } \\
\text { emprego, mercado do trabalho, organização } \\
\text { profissional, relações laborais }\end{array}$ & Econômica \\
\hline Direito e justiça & $\begin{array}{l}\text { Termos de direito e justiça, direito, direito civil, direito } \\
\text { internacional, direito penal, direitos e liberdades, fontes } \\
\text { e ramos do direito, justiça e organização da justiça. }\end{array}$ & Política \\
\hline Política & $\begin{array}{l}\text { Administração pública, assembleia, ciência política, } \\
\text { partido político, poder executivo, quadro político, } \\
\text { trabalhos parlamentares, vida política. }\end{array}$ & Política \\
\hline $\begin{array}{l}\text { Informação e } \\
\text { tratamento }\end{array}$ & $\begin{array}{l}\text { Documentação, gestão da informação, gestão } \\
\text { eletrônica documental, tratamento da informação. }\end{array}$ & Econômica \\
\hline
\end{tabular}

Fonte: Elaboração pesquisa própria (2017) 
Utilizamos as técnicas da análise de conteúdo (BARDIN, 2011) na operacionalização da investigação, buscando realizar uma pesquisa com rigor científico e possibilitar uma análise mais robusta à abordagem (OLIVEIRA et. al., 2003), ademais, considerando o caráter não hermético do campo de análise das ciências humanas do qual o trabalho se filia (LEMOS, 2017).

A partir das evidências encontradas nos textos normativos, considerando as categorias de análise elencadas, buscou-se, complementarmente, a compreensão por meio de entrevistas estruturadas aplicadas junto aos sujeitos (5 diretores das 5 escolas na zona urbana da rede pública municipal de Santo Amaro-BA) a identificação dos discursos, compreensões e efetivação das práticas de gestão escolar a fim de comparar, ratificar e substantivar os achados iniciais da análise documental e exploratória com os resultados do campo empírico, ampliando a consistência dos achados científicos (LEMOS, 2017).

A análise de conteúdo que é assumida nesse estudo foi efetivada com a utilização do software Tropes de análise semântica. Essa ferramenta foi desenvolvida, preliminarmente, pelo pesquisador Pierre Molette em 1994, em parceria com a Universidade Paris 8, posteriormente, com a colaboração da empresa Acetic/Ciberlex Semantic-Knowledge.

O software Tropes constitui-se em um dos primeiros programas baseado em redes semânticas, que realiza a análise e extração das informações mais relevantes de um texto envolvendo a identificação do estilo do texto, retirada do sentido ambíguo, categorização e classes de palavras e elaboração de gráficos.

A representação esquemática do percurso metodológico adotado está evidenciada na Figura-1.

Figura 1 - percurso metodológico

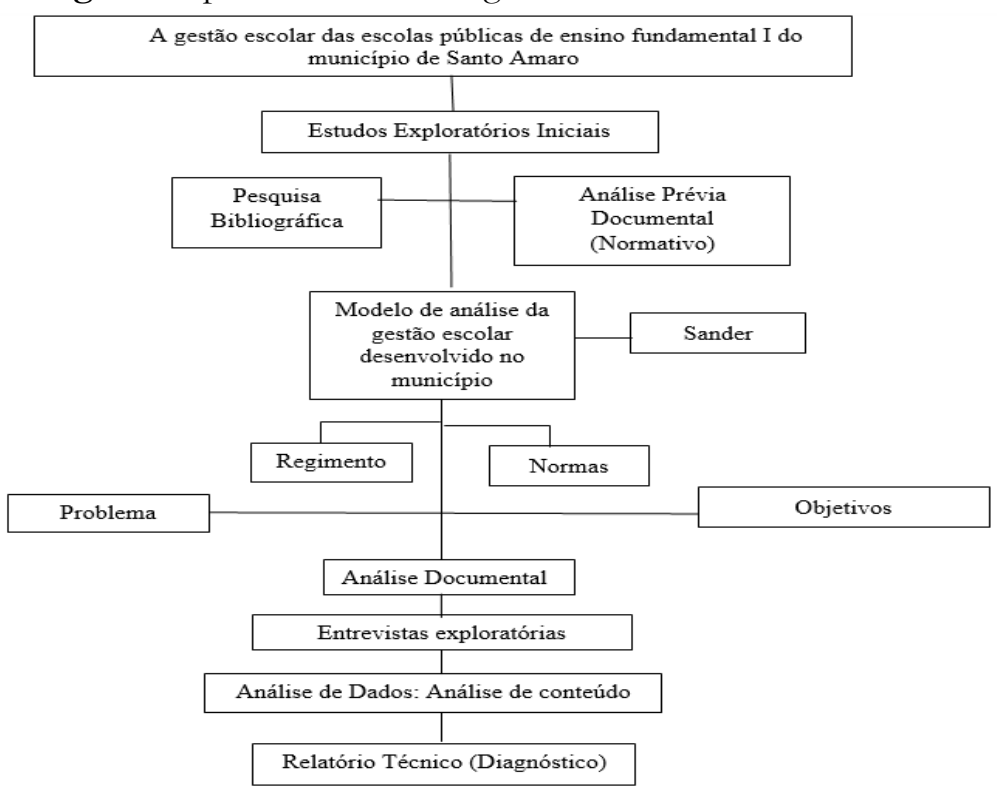

Fonte: Pesquisa elaboração própria 


\section{Resultados obtidos}

A partir de uma abordagem documental e exploratória com a utilização do Tropes, fundamentada na frequência de identificação de determinados termos e elementos na legislação municipal, possibilitou uma caracterização das categorias iniciais, conceitos intermediários, e, das categorias correlacionadas as dimensões propostas pelo estudo.

Nesse sentido, possibilitou a identificação ou reconhecimento maior e menor da perspectiva multidimensional do papel do diretor escolar no âmbito da gestão escolar da zona urbana de Santo Amaro (BA), e, a ratificação desses achados com as inferências obtidas junto as entrevistas realizadas com esses sujeitos.

A investigação possibilitou evidenciar frequências, ausências, similaridades e assimetrias desses marcos normativos em relação ao modelo teórico proposto na literatura por Sander (1995, 2007), consequentemente, o grau de aderência, aproximações e distanciamentos do arranjo normativo local em relação a gestão escolar da rede municipal de Santo Amaro no reconhecimento das dimensões econômicas, políticas, culturais e pedagógicas na efetivação das possíveis práticas dos gestores escolares (Quadro 1).

Identificou-se no estudo dos marcos normativos, quem pode ser um gestor na rede de ensino municipal de Santo Amaro (BA), entretanto, não consta uma sistematização de suas práticas nem definição mais clara de suas funções (SANTO AMARO, 2002, caput art. 40).

O cargo de diretor escolar no município é assumido mediante nomeação pelo chefe do poder executivo municipal (prefeito) não havendo, portanto, processo eleitoral para escolha dos gestores escolares, a despeito do Plano Municipal de Educação do Município prever como meta até 2025 “assegurar que o corpo gestor da unidade escolar seja composto por profissionais efetivos com formação específica em educação, por meio de processo eletivo normatizado pela Secretaria Municipal de Educação" (SANTO AMARO, 2015, p. 39) conforme diretriz presente no Plano Nacional de Educação (PNE) (BRASIL, 2014).

A partir da análise do conjunto normativo em vigor, os resultados indicaram que os diretores escolares são pautados a exercer uma função de forma mais difusa, onde aspectos mais pertinentes da ação burocrática, confundem-se, muitas vezes sobrepondo-se, a aspectos políticos, pedagógicos e culturais.

A análise dos documentos normativos sinalizou a maior sensibilização da dimensão política (identificada na inserção de 2.194 termos nos documentos oficiais) - Gráfico 1.

O Gráfico 2 a partir da representação polar, demonstra o nível de sensibilização da dimensão política nos documentos oficiais analisados na pesquisa (estatuto dos servidores, regimento escolar, plano de carreira dos profissionais de educação e o regimento jurídico dos servidores). 
Percebemos que quanto maior for a área de expansão do gráfico, maior o nível de sensibilização do documento oficial em relação a dimensão analisada. Nesse sentido, evidencia-se, portanto, que o plano de carreira dos servidores municipais e o regime jurídico único dos servidores públicos municipais estão mais sensibilizados a dimensão política, de outro modo, o estatuto dos profissionais de educação e o regimento escolar são menos sensibilizados pela dimensão política.

Gráfico 1 - Incidência das dimensões da gestão multidimensional nos documentos normativos

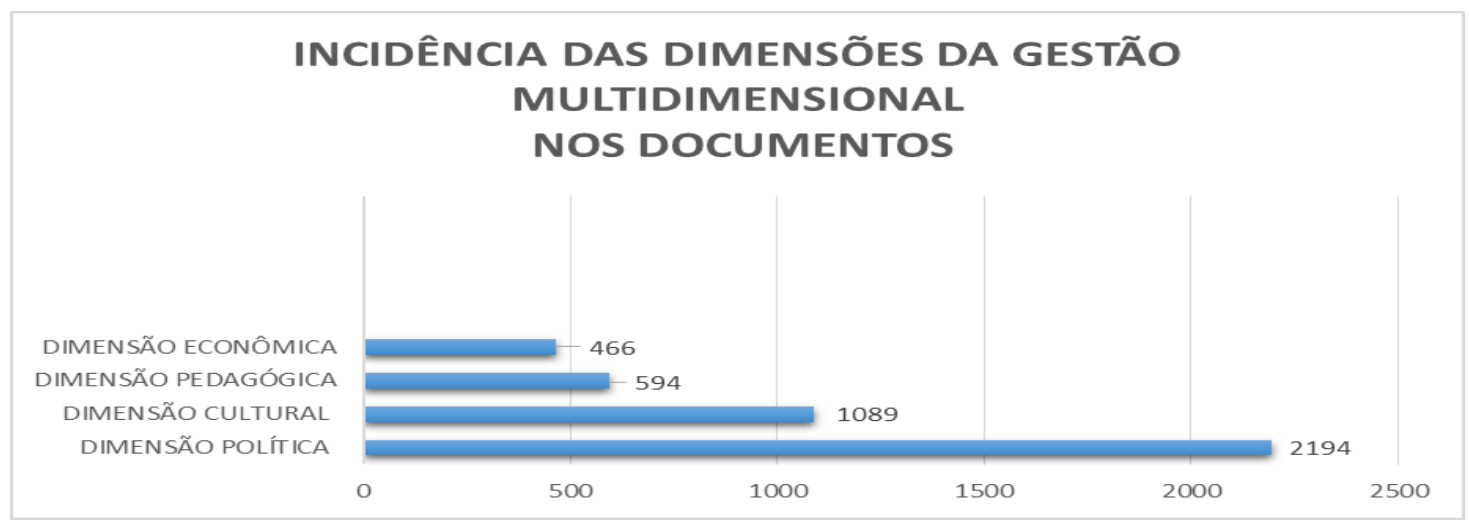

Fonte: Elaboração própria a partir do software Tropes.

Deste modo, podemos inferir que a perspectiva política, que pauta a ação dos diretores escolares, está sinalizada, prioritariamente, nos documentos oficias de caráter mais amplo (plano de carreira dos servidores municipais e sistema jurídico único), sendo os documentos mais específicos do campo escolar e educacional (estatuto do magistério e regimento escolar) menos sensibilizados por essa perspectiva (Gráfico 2).

Nas entrevistas realizadas, com os 5 diretores das 5 escolas que formam a zona urbana de Santo Amaro (BA) percebemos a preocupação de monitoramento das demandas da comunidade escolar em perspectiva mais ampla que as questões meramente curriculares, algo bastante significativo:

É político quando chama as mães para fazer uma palestra, por exemplo para falar da dengue, além de outros assuntos, precisamos realmente está chamando a comunidade para participar. Eu acho que isso se torna político e cultural também. A escola é aberta. (Entrevistado 1). 
Gráfico 2 - Grau de sensibilização da dimensão política

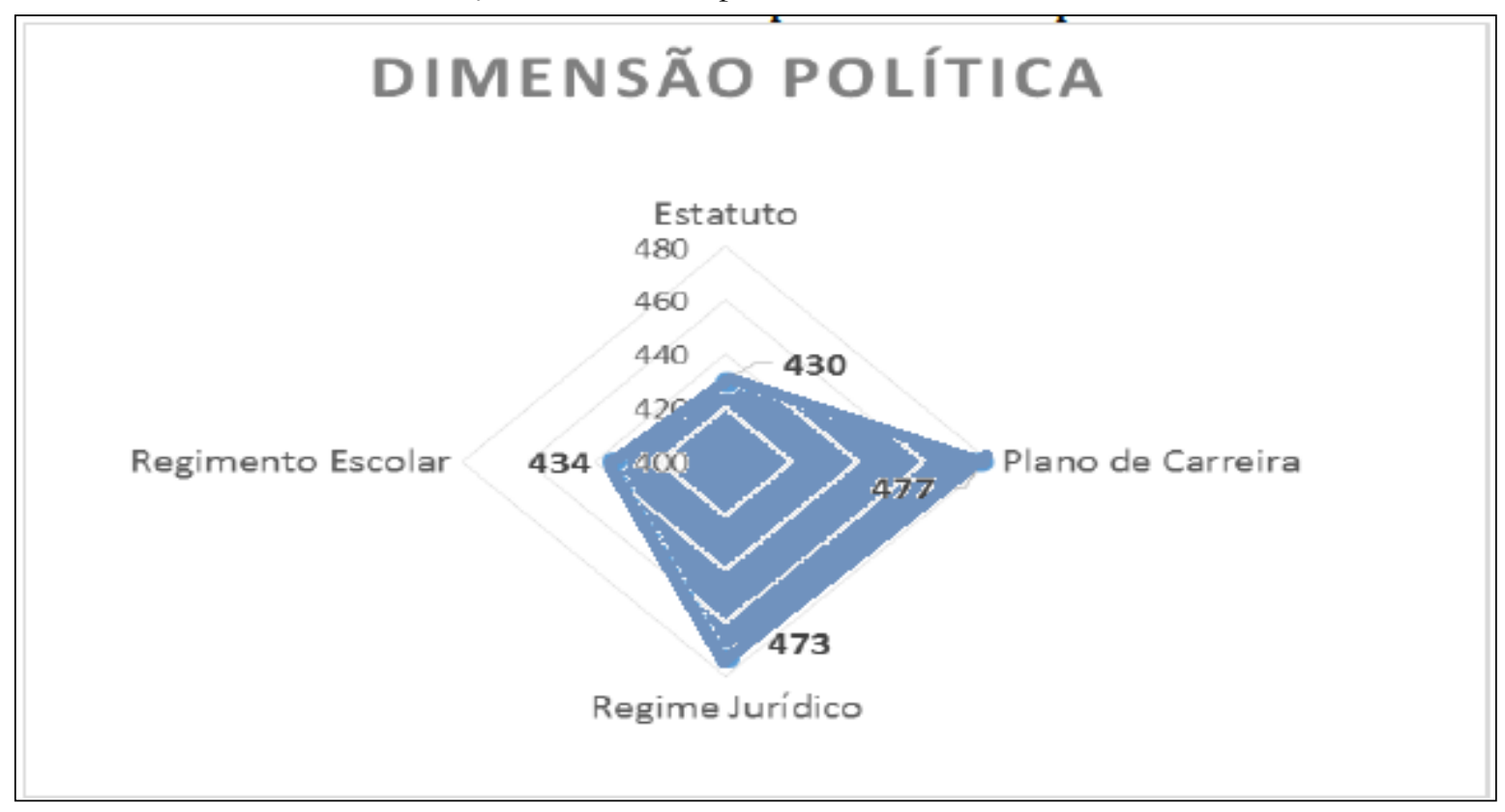

Fonte: Elaboração própria a partir do software Tropes.

Nesse sentido, a dimensão política é compreendida como aquela que prepara e estimula para o convívio coletivo, da comunidade escolar, na qual os diversos sujeitos (professores, estudantes, profissionais, pais e cidadãos do entorno escolar) possam conviver de forma democrática, para os quais o esforço da gestão escolar deve sensibilizar-se as demandas por acesso ao direito a educação pública.

A dimensão cultural, correspondeu segunda categoria mais sensibilizada na análise dos documentos normativos (identificada na inserção de 1.089 termos nos documentos oficiais) Gráfico 1. 
Gráfico 3 -Grau de sensibilização da dimensão cultural

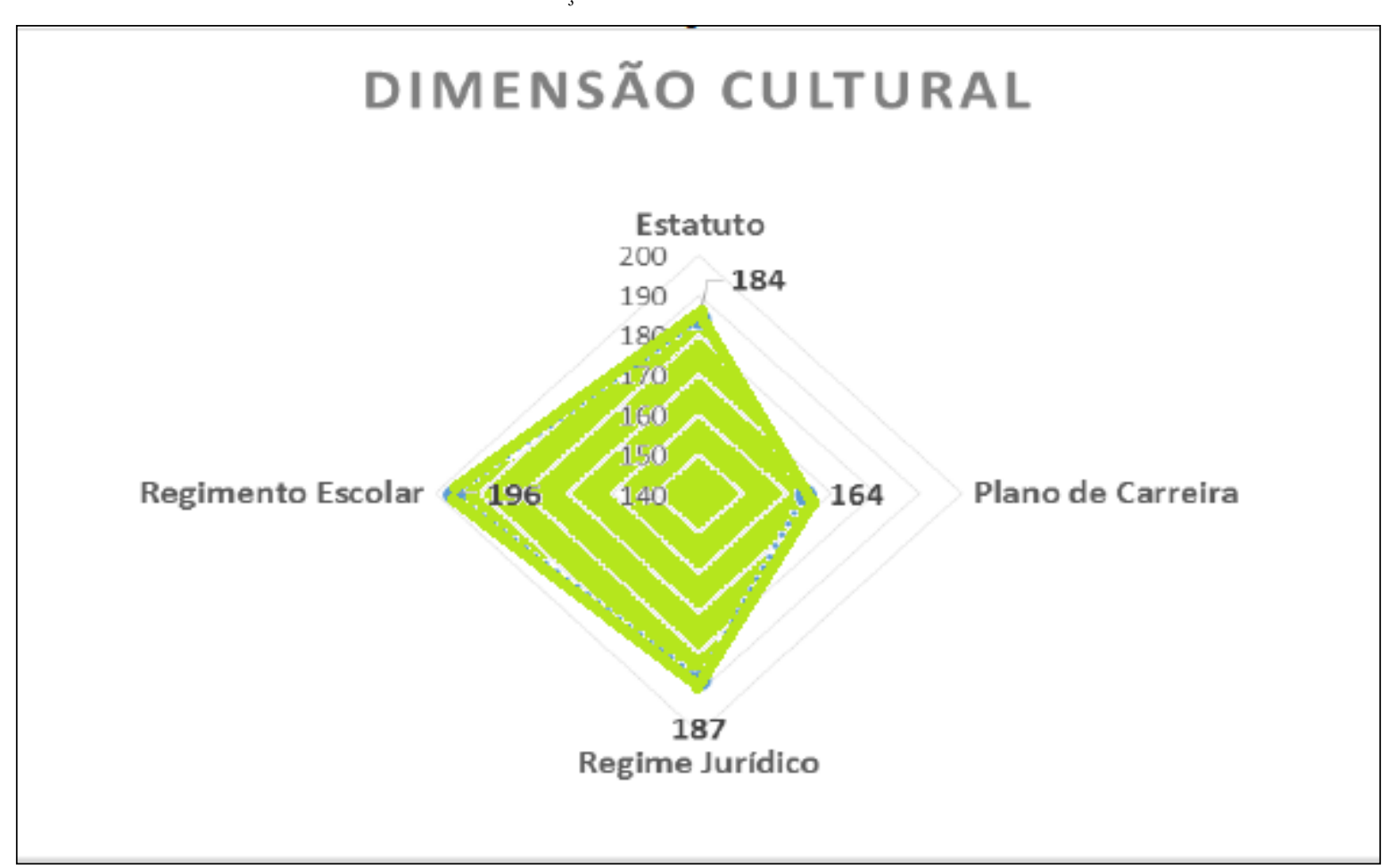

Fonte: Elaboração própria a partir do software Tropes.

O Gráfico 3 a partir da representação polar, demonstra o nível de sensibilização da dimensão cultural nos documentos oficiais analisados na pesquisa (estatuto dos servidores, regimento escolar, plano de carreira dos profissionais de educação e o regimento jurídico dos servidores).

Percebemos que quanto maior for a área de expansão do gráfico, maior o nível de sensibilização do documento oficial em relação a dimensão analisada. Nesse sentido, evidencia-se, portanto, que o regimento escolar, o estatuto do magistério e o regimento jurídico único dos servidores municipais estão mais sensibilizados a dimensão cultural, de outro modo, o plano de carreira dos servidores públicos municipais é menos sensibilizado pela dimensão cultural (Gráfico 3).

Deste modo, podemos inferir que a perspectiva cultural, que pauta a ação dos diretores escolares, está sinalizada tanto nos documentos oficias de caráter mais amplo (regime jurídico único) quanto nos documentos mais específicos do campo escolar e educacional (estatuto do magistério e regimento escolar), sendo o plano de carreira dos servidores municipais menos sensibilizado por essa perspectiva (Gráfico 3).

Os depoimentos captados na realização das entrevistas, observamos que a dimensão cultural está articulada com o reconhecimento das expressões culturais populares vivenciados nas dinâmicas pedagógicas escolares:

[...] quando a gente abre a escola, quando a gente convida os pais, com a culminância de projetos, quando convidamos a comunidade, quando levamos alunos também ao teatro e também quando abrimos para a comunidade assistir à apresentação de alunos.

(Entrevistado 2). 
É importante destacar que a dimensão cultural deve ser entendida em sentido mais amplo, considerando tudo aquilo produzido pelo homem como valores, conhecimentos, crenças, costumes, enfim, produtos de sua história. Logo, nesta dimensão deve haver tal mediação entre a formação da personalidade do estudante por meio da apropriação da cultura, permitindo a criação da cultura e a consequente transformação social.

A análise dos documentos normativos sinalizou a dimensão pedagógica apenas como a terceira dimensão sensibilizada (identificada na inserção de 594 termos nos documentos oficiais) -

\section{Gráfico 1.}

O Gráfico 4 a partir da representação polar, demonstra o nível de sensibilização da dimensão pedagógica nos documentos oficiais analisados na pesquisa (estatuto dos servidores, regimento escolar, plano de carreira dos profissionais de educação e o regimento jurídico dos servidores).

Percebemos que quanto maior for a área de expansão do gráfico, maior o nível de sensibilização do documento oficial em relação a dimensão analisada. Nesse sentido, evidencia-se, portanto, que o plano de carreira dos servidores municipais, o estatuto do magistério e o regime escolar estão mais sensibilizados a dimensão pedagógica, de outro modo, o regime jurídico único dos servidores está menos sensibilizado pela dimensão pedagógica (Gráfico 4).

Naturalmente, os documentos oficiais dedicados ao cotidiano escolar (regimento escolar e estatuto do magistério) devem sensibilizar mais a dimensão pedagógica dado a própria especificidade dos mesmos, do mesmo modo, que o regime jurídico único dos servidores, documento de caráter mais amplo e geral, seja menos sensibilizado nessa dimensão (Gráfico 4).

Gráfico 4 - Grau de sensibilização da dimensão pedagógica

\section{DIMENSÃO PEDAGÓGICA}

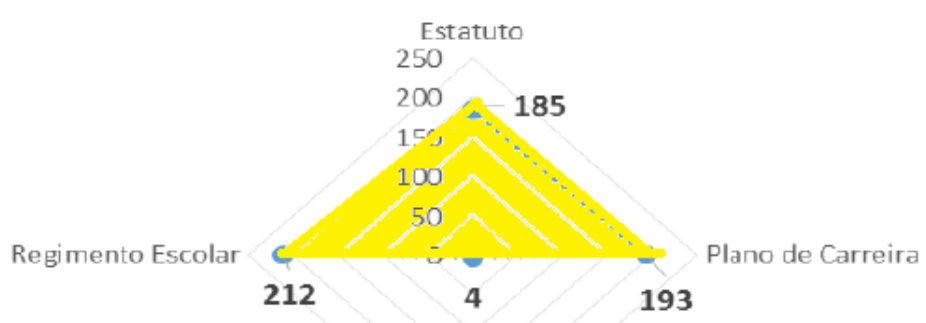

Regime Jurídico

Fonte: Elaboração própria a partir do software Tropes 
Os resultados demonstraram, quanto a dimensão pedagógica, não ser a dimensão mais sensibilizada, o que acabou confirmando a hegemonia da dimensão política, como sinalizado em outros estudos (SANDER, 2007; NOGUEIRA, 2002; SILVA JÚNIOR, 1993) para o conjunto de documentos que norteiam a gestão escolar da rede municipal de Santo Amaro (BA).

Nas entrevistas realizadas, percebemos a clara demanda dos diretores escolares por uma normatização mais efetiva das práticas pedagógicas e orientadoras realizadas no cotidiano escolar, a busca por proteção quanto a casuísmos ou improvisos, especialmente, norteando o trabalho dos diretores escolares:

Hoje na nossa escola tem um regimento que fica para os professores olharem. O regimento para a escola é muito bom por que respalda não só o diretor, mas a escola. Eu acho que o Regimento respalda, eu vou te falar o que acontece, dentro do Regimento na nossa escola, no caso de reprovação se o aluno for bom, o Regimento diz que podemos reprovar o aluno por causa das faltas, casos de alunos agressivos nós buscamos pesquisar o Regimento para que possamos estar mais seguras e ver a decisão a ser tomada na escola. (Entrevistado 3).

Por fim, a análise dos documentos normativos sinalizou a dimensão econômica apenas como a quarta dimensão sensibilizada (identificada na inserção de 466 termos nos documentos oficiais), contrariando a suposta hegemonia sinalizada em outros estudos (SANDER, 2007; NOGUEIRA, 2002; SILVA JÚNIOR, 1993), resultado a ser assumido com relativa parcimônia - Gráfico 1.

O Gráfico 5 a partir da representação polar, demonstra o nível de sensibilização da dimensão econômica nos documentos oficiais analisados na pesquisa (estatuto dos servidores, regimento escolar, plano de carreira dos profissionais de educação e o regimento jurídico dos servidores).

Percebemos que quanto maior for a área de expansão do gráfico, maior o nível de sensibilização do documento oficial em relação a dimensão analisada. Nesse sentido, evidencia-se, portanto, que o regime jurídico dos servidores públicos municipais, o plano de carreira dos servidores municipais e o estatuto do magistério estão mais sensibilizados a dimensão econômica, de outro modo, o regimento escolar é menos sensibilizado pela dimensão econômica (Gráfico 5).

Deste modo, podemos inferir que a perspectiva econômica, que pauta a ação dos diretores escolares, está sinalizada, tanto nos documentos oficias de caráter mais amplo (plano de carreira dos servidores municipais e regime jurídico único dos servidores) quanto nos documentos mais específicos do campo escolar e educacional (estatuto do magistério). O regimento escolar, é o documento oficial menos sensibilizados por essa perspectiva (Gráfico 5).

Os resultados apresentados, de algum modo, negaram parcialmente as perspectivas quanto a hegemonia da dimensão econômica sobre as demais (SANDER, 2007; NOGUEIRA, 2002; SILVA JÚNIOR, 1993) considerando que a análise dos marcos normativos da rede municipal de Santo Amaro (BA) e as entrevistas realizadas com os diretores escolares apenas sensibiliza essa dimensão em última, sem negar, entretanto, outras possibilidades de inserção hegemônica dessas dimensões. 
Gráfico 5 - Grau de sensibilização da dimensão econômica

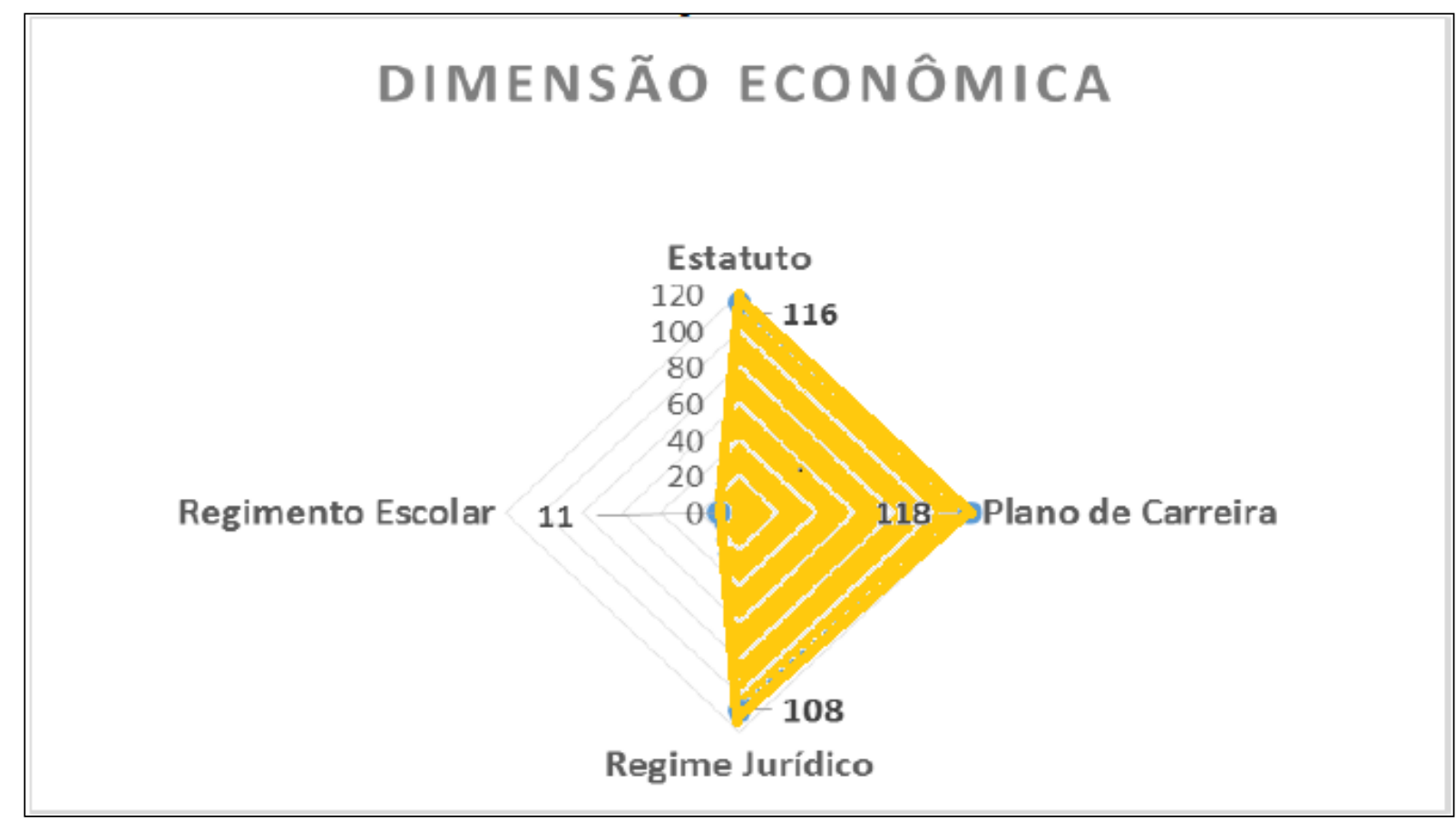

\section{Considerações finais}

O estudo analisou, por meio da revisão bibliográfica, documental, exploratória e descritiva o papel do diretor das escolas públicas da rede municipal de Santo Amaro (BA) na perspectiva da gestão escolar sob a perspectiva do paradigma multidimensional (SANDER, 1995, 2007).

A pesquisa determinou as categorias de análise a partir das dimensões pedagógicas, culturais, políticas e econômicas presentes nessa literatura, para análise documental dos marcos normativos municipais, levantamento de termos presentes nesses documentos, categorias iniciais, intermediárias e sua correlação com as categorias de análise do estudo, e, complementado com inferências do campo empírico das práticas dos diretores escolares com aplicação de entrevistas estruturadas.

Os resultados do estudo evidenciaram que o ingresso dos profissionais da educação a função de diretor escolar na rede municipal de Santo Amaro é realizado através de nomeação, que considera, supostamente, o mérito da função de confiança.

Essa prática acaba por influenciar na gestão escolar da rede municipal estudada, a despeito de o Plano Municipal de Educação do Município prever como meta até 2025 “assegurar que o corpo gestor da unidade escolar seja composto por profissionais efetivos com formação específica em educação, por meio de processo eletivo normatizado pela Secretaria Municipal de Educação” (SANTO AMARO, 2015, p. 39). 
Os achados da pesquisa, indicam um reconhecimento relativo das dimensões presentes nos pressupostos teóricos do paradigma multidimensional, destacados nos documentos, pela ordem, a dimensão política, posteriormente a dimensão cultural, seguida da pedagógica e, por último, com menor incidência nos documentos normativos, a dimensão econômica, nesse sentido, negando a hegemonia da dimensão econômica sobre as demais dimensões no conjunto das práticas do cotidiano escolar conforme sinalizado em outros estudos mas ratificando o papel relevante da dimensão política e a relativa atrofia da dimensão pedagógica nesse fenômeno (SANDER, 2007; SILVA JÚNIOR, 1993; NOGUEIRA, 2002). Os riscos da menor incidência da dimensão pedagógica são previsíveis.

De outro modo, a prevalência da dimensão política, detectada no estudo, pode colaborar para uma compreensão demagógica e estreita do papel do diretor escolar, entendendo, indevidamente, sua atuação como mero ator no cenário burocrático alinhado a perspectivas político-ideológicas do órgão central de educação ou do chefe do poder executivo local, pouco comprometido com as referências culturais e políticas da comunidade escolar, e, naturalmente indiferente quanto à eficácia das práticas pedagógicas relacionadas ao ensino-aprendizagem efetivadas no ambiente escolar.

Os resultados da pesquisa recomendam um aperfeiçoamento da legislação normativa, que não especifica ou comtempla a dinâmica do trabalho do diretor escolar, e está demandada pelos sujeitos, e, a implementação de um programa de formação continuada em serviço voltada aos servidores, especialmente, para o que se encontram em exercício da função de diretor escolar, com base nos princípios de uma escola democraticamente referenciada, em que a dimensão pedagógica pauta a inserção das dimensões políticas, culturais e econômicas.

O trabalho apresenta resultados do contexto do papel do diretor escolar no âmbito da rede municipal de Santo Amaro (Ba), vigentes no recorte documental a partir de 2002 e vigentes em 2017, período abrangido na pesquisa, a partir de uma abordagem de caráter qualitativo, documental e exploratório, portanto, os resultados e inferências ora apresentados não são sujeitos a generalizações a outros cenários educacionais, políticos, geográficos, territoriais ou econômicos, para os quais novos estudos devem ser realizados.

\section{Referências}

BARDIN, Laurence. Análise de Conteúdo. Lisboa: Edições 70, 2011.

BARROSO, João. Para uma abordagem teórica da reforma da administração escolar: a distinção entre direção e gestão. Revista Portuguesa de Educação, Minho, Portugal, v. 8, n. 1, p. 33-56, 1995.

BARROSO, João. Gestão local da educação: entre o estado e o mercado, a responsabilização coletiva. In: MACHADO, Lourdes Marcelino; FERREIRA, Naura Syria (Orgs.). Política e gestão da educação: dois olhares. Rio de Janeiro: DP\&A; ANPAE, 2002. p. 173-198. 
BRASIL (Constituição). Constituição de República Federativa do Brasil de 1988. Brasília: Senado Federal, 1988. Disponível em: < http://www.planalto.gov.br/ccivil_03/constituicao/constituicao.htm >. Acesso em: 02 jun. 20018.

BRASIL. Lei complementar no. 13.005, de 25 de junho de 2014. Aprova o Plano Nacional de Educação - PNE e dá outras providências. Diário Oficial [da] República Federativa do Brasil, Brasília, DF, 25 jun. 2014. Disponível em: <http://www.planalto.gov.br/ccivil_03/_ato20112014/2014/lei/113005.htm>. Acesso em: 05/09/2017.

CONCEIÇÃO, Sergio Henrique. Conselhos Fundeb: gestão democrática e qualidade da educação pública. Saarbrűcken: Novas edições acadêmicas, 2016.

INSTITUTO NACIONAL DE ESTUDOS E PESQUISAS EDUCACIONAIS (IBGE). Censo Escolar: Resultados e Resumos. Brasília: INEP; FNDE, 2016. Disponível em: <http://portal.inep.gov.br/resultados-e-resumos>. Acesso em: 12 maio 2016.

INSTITUTO NACIONAL DE ESTUDOS E PESQUISAS EDUCACIONAIS (IBGE). Portal Cidades: Santo Amaro, BA. Rio de Janeiro: IBGE, 2015. Disponível em: <http:/ /www.cidades.ibge.gov.br/xtras/temas.php?lang=\&codmun=292860\&idtema=16\&search =bahia $\mid$ santo-amaro $\mid$ sintese-das-informacoes $>$. Acesso em: 12 maio 2016.

LEMOS, Hirlana de Freitas. Gestão Escolar: O papel do diretor das escolas públicas da rede municipal de Santo Amaro na perspectiva do paradigma multidimensional. Programa de Pós-Graduação em Gestão e Tecnologias aplicadas à Educação (Mestrado Profissional). Relatório Técnico, Salvador, 2017, f. 242.

LIMA, Licínio. A escola como organização educativa. São Paulo: Cortez, 2001.

LÜCK, Heloísa. Dimensões de gestão escolar e suas competências. Curitiba: Editora Positivo, 2009.

NOGUEIRA, Marco Aurélio. Administrar e dirigir: algumas questões sobre a escola, a educação e a cidadania. In: MACHADO, Lourdes Marcelino; FERREIRA, Naura Syria (Orgs.). Política e gestão da educação: dois olhares. Rio de Janeiro: DP\&A; ANPAE, 2002. p. 17-32.

OLIVEIRA, Eliana:; ENS, Romilda Teodora; ANDRADE, Daniela B.S.Freire; MUSSIS, Carlo Ralph de. Análise de Conteúdo e Pesquisa na Área da Educação. Revista Diálogo Educacional, Curitiba, v. 4, n.9, maio/ago. 2003. p.11-27.

PARENTE, Juliano Mota. Gerencialismo e performatividade na gestão educacional do estado de São Paulo, 2016, 134f, Tese (Doutorado em Educação), - Universidade Estadual Paulista, Faculdade de Ciências e Tecnologia, Presidente Prudente, 2016.

PARO, Vitor Henrique. A educação, a política e a administração: reflexões sobre a prática do diretor de escola. Educ. Pesqui., São Paulo, v. 36, n. 3, p. 763-778, set./dez. 2010. Disponível em: <http://www.scielo.br/pdf/ep/v36n3/v36n3a08.pdf>. Acesso em: 28 maio 2017.

PARO, Vitor Henrique Administração escolar: introdução crítica. São Paulo: Cortez, 1993.

SANDER, Benno. Gestão da educação na América Latina: construção e reconstrução do conhecimento. Campinas: Autores Associados, 1995. 136p. (Coleção educação contemporânea).

SANDER, Benno. Administração da educação no Brasil: genealogia do conhecimento. Brasília: Liber Livro, 2007. 136p.

SANDER, Benno $\mathrm{O}$ estudo da administração da educação na virada do século. In: MACHADO, Lourdes Marcelino; FERREIRA, Naura Syria (Orgs.). Política e gestão da educação: dois olhares. Rio de Janeiro: DP\&A; ANPAE, 2002. p. 55-68. 
SANTO AMARO (Município). Lei no. 1432, de 03 de julho de 2002. Dispõe sobre o Estatuto do Magistério Público do Município de Santo Amaro. Jornal Oficial do Município de Santo Amaro, Santo Amaro, BA, jul. 2002.

SANTO AMARO (Município). Lei nº. 1463, de 31 de janeiro de 2003. Dispõe sobre o Plano de Carreira e Remuneração dos Servidores do Magistério. Jornal Oficial do Município de Santo Amaro, Santo Amaro, BA, ed. 2476, p. 10, fev. 2003.

SANTO AMARO (Município). Lei $\mathrm{n}^{\circ}$. 1465, de 31 de janeiro de 2003. Dispõe sobre o Sistema Jurídico Único dos servidores da administração direta, das autarquias e das fundações do Município de Santo Amaro. Jornal Oficial do Município de Santo Amaro, Santo Amaro, BA, ed. 2476, p. 19, fev. 2003.

SANTO AMARO (Município). Regimento Escolar Unificado da Rede Pública Municipal. Santo Amaro, BA: Secretaria Municipal de Educação, 2011.

SEMANTIC KNOWLEDGE. Tropes version 7.2.3 - ACETIV. Semantic Search Engine, Text Analysis \& Semantics Software. Paris, 2016. Disponível em: <https://www.semanticknowledge.com/>. Acesso em: 01 jul. 2017.

SILVA JÚNIOR, Celestino Alves da. A escola pública como local de trabalbo. 2. Ed. São Paulo: Cortez, 1993.

TEIXEIRA, Anísio Spínola. A educação e a crise brasileira. Rio de Janeiro: UFRJ, 2005 (Col. Anísio Teixeira, v.5).

Recebido em: 24 jan. 2019 / Aprovado em: 29 out. 2019

\section{Para referenciar este texto}

CONCEIÇÃO, Sérgio Henrique; LEMOS, Hirlana Freitas de. O papel do diretor das escolas públicas da rede municipal de Santo Amaro (BA). Cadernos de Pós-graduacãa, São Paulo, v. 18, n. 2, p. 122-137, jul./dez. 2019. Disponível em: < https://doi.org/10.5585/cpg.v17n1.11399>. 